\title{
Essentials of Doctoral Education: Organization of Program Around Knowledge Areas
}

\author{
Shaké Ketefian, EdD, RN, FAAN*
}

\begin{abstract}
This article presents a case study describing how one nursing doctoral program faculty has identified, organized, and taught the disciplinary knowledge component of the curriculum. Three foci were chosen: health promotion and risk reduction; acute, critical, and long-term care; and systems. Faculty groups designed each focus to capitalize on current faculty research strengths and did not use a formalized knowledge structure a priori. Scholarship content and sample courses are described. Factors affecting implementation included providing students with choice; a mixture of full-time and part-time students; little interchangeability of faculty in courses; balancing doctoral teaching with teaching at other levels; advisement issues; a lengthy formal curriculum approval process; and highly specific needs of individual students. Initial reflection shows the possibility of integrating the research methods content into the disciplinary courses in light of their interdependence; help gained through the process in achieving clarity about what the school wishes to be known for; the necessity of a critical mass of faculty with active research programs along with commitment to program enrichment; the role of the foci in providing intellectual sustenance and mutual faculty mentorship; and concern about the inability to fit of some faculty. (Index words: Nursing; Curriculum; Doctoral; Education). J Prof Nurs 9:255-261, 1993. Copyright (c) 1993 by W.B. Saunders Company
\end{abstract}

*Professor and Director, Doctoral and Postdoctoral Studies, The University of Michigan School of Nursing, Ann Arbor, MI.

Paper presented at the American Association of Colleges of Nursing Doctoral Conference, "Moving Beyond Traditional Boundaries: Diverse Models for Structuring Knowledge and Funding Doctoral Education," Sanibel Island, FL, January 30 , 1992.

Address correspondence and reprint requests to Dr Ketefian: The University of Michigan School of Nursing, 400 North Ingalls, Ann Arbor, MI 48109.

Copyright (C) 1993 by W.B. Saunders Company

$8755-7223 / 93 / 0905-0005 \$ 3.00 / 0$
THIS ARTICLE presents a case study describing 1 how one doctoral program faculty has dealt with the disciplinary knowledge component of the curriculum: how it is organized, how it is identified, and how it is taught. In doing so, the article also deals with the fit of this curricular component with other components and raises issues related to its implementation.

Doctoral education is now at a crossroads. The last decade has seen a phenomenal expansion in doctoral education nationally and in the number of individuals qualified to teach in these progtams. Historically, the majority of our doctoral programs have concentrated their energies on teaching what I call "process" courses: research methods, statistics, theory development, history of nursing, philosophy of science, and the like. In addition, students have been guided in the selection of cognate courses from other disciplines, which then, in effect, have become the substantive component of their program of study.

More recently, there has been a growing interest in teaching substantive courses in the discipline of nursing. The dramatic turning point for this shift in focus was the first American Association of Colleges of Nursing conference on doctoral education in San Antonio, where Meleis (1988) made a plea for a "passion for substance" and away from what she called "methodological oppression." Since then we have concerned ourselves largely with questions that elucidate the substantive, disciplinary content of our programs.

This is salutary in the extreme and indicates a major milestone in the maturity of our thinking. This is not to say that we have reached our goal, only that the matter is uppermost in our minds, and sincere efforts are underway to get us to where we now know we should be. 


\section{Goals and Issues}

Given that we agree on this general aim-that substantive disciplinary knowledge should have primacy in our doctoral programs-we can begin to develop specific goals and questions to be addressed. In determining what disciplinary knowledge should be taught at the doctoral level, the two goals of compelling importance are (1) determining, organizing, and teaching the advanced knowledge in nursing that we consider essential for our students, and (2) identifying the gaps in knowledge that need to be pursued by ourselves and our students (the gaps that, when filled, will expand the scientific knowledge base for nursing).

With regard to identifying nursing knowledge, one of the issues that has been discussed by various authors relates to the need for "organizing" or "structuring" this knowledge and how such structuring is to occur. For example, Ellis (1984) made her case in this manner: "A body of knowledge and a field of inquiry must be organized and structured, and both, by nature, are reshaped by research and theory development" (p. 1). Similarly, Donaldson and Crowley (1978) made a plea toward the same end: "There is also a crucial need for identification of the structure of the discipline of nursing in our educational program" (p. 114), and clarified the fact that they were advocating not the construction of a structure for the discipline but rather the explication of that structure. Donaldson and Crowley have helpfully provided a definition of "structure" as "the broad conceptualizations and syntax of the discipline rather than the theories generated within this structure" (p. 114).

We have in general "bought into" this argument, and over time various approaches have been presented in the literature for structuring nursing knowledge. Thus, during the 1989 Doctoral Forum meeting, three different approaches were discussed that might serve as the conceptual basis for organizing and advancing nursing knowledge: using clinical content and nursing specialties (Walker, 1989), using metaparadigm domain concepts (Kim, 1989), and using nursing diagnosis/taxonomy (Fitzpatrick, 1989).

There are good reasons for not articulating the structure of knowledge a priori but rather focusing on the development of knowledge first. Furthermore, even in the well-established disciplines, there is seldom a single accepted organizational schema (Fry, 1988).

\section{Reaching Consensus on Foci}

When our faculty systematically began deliberations about inclusion of substantive nursing content in the doctoral curriculum in the mid 1980s, a variety of approaches were considered and debated. After a year of debate, two things became clear: consensus was very difficult because of the diversity of views, and because the more specific the approach, the harder it was to achieve consensus; conversely, that the more general the approach, the easier it was to achieve a consensus. After another year of debate, two other things became clear: (1) the faculty was ready to endorse a broad conceptualization of nursing for our curriculum, and (2) there was a growing sense that we should "get on with it."

During this period, the American Nurses Association's (ANA) Cabinet on Nursing Research issued its document "Directions for nursing research: Toward the twenty-first century" (ANA, 1985), which influenced faculty thought. We therefore decided that there would be three foci in our substantive nursing offerings: (1) health promotion and risk reduction; (2) acute, critical, and long-term care; and (3) systems, including nursing and health care delivery systems. Parenthetically, shortly thereafter the school adopted these as the bases for our "intellectual thrusts" around which faculty/doctoral student research interest groups were formed; more recently, these have formed the basis for reorganizing the administrative structure within which the school's academic programs are conducted. These unanticipated developments served to reinforce our efforts within the doctoral program.

\section{... the more specific the approach, the harder it was to achieve consensus ...}

In retrospect, we were not very concerned with a formalized knowledge structure. What we were seeking was an umbrella, a rubric, that would help students think in critical ways about the discipline and make sense of their learning and within which we could embrace the many ongoing faculty research programs on nursing phenomena. Most importantly, we did not want a structure that limited inquiry. Rather, we wanted an approach that was open-ended, that would allow emerging research-based knowledge to be recognized and, perhaps at a later point, shape and reshape the disciplinary structure. This is in line with what we have seen in the social sciences, where some scholars are moving toward a "deconstruction" and "dismantling" of knowledge structures that have constrained inquiry within various disciplines (Fry, 1988) 
Figure 1. Conceptual and organization framework for graduate programs at The University of Michigan School of Nursing. (Details provided only for the health promotion/risk reduction focus.)
INGUIRY AND CURRICULA

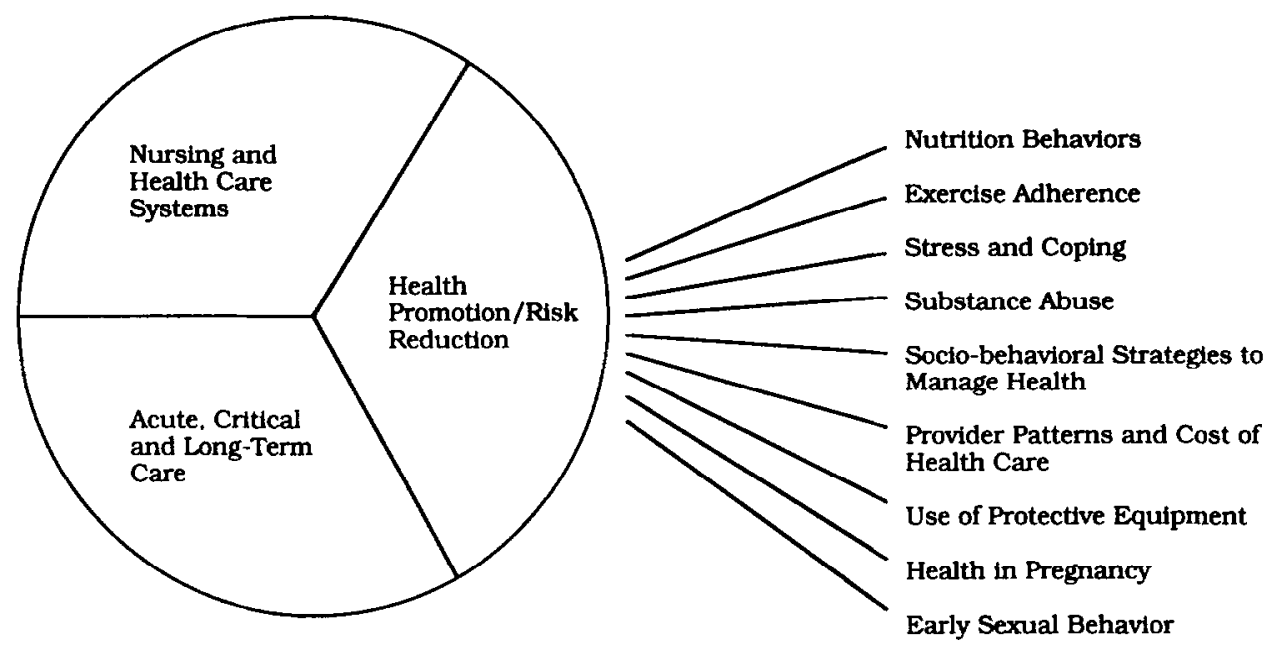

and toward a growing emphasis on multidisciplinary research.

This is not to say that a certain degree of organization was not helpful. Indeed, without this it is difficult to design a coherent curriculum for our learners. This concern guided our thinking on how we might go about developing each of the three identified foci. *

\section{Development of the Foci for Nursing Specialization}

Different faculty groups were assembled to define the scope of the identified specializations and to propose the courses within each. Because many individuals were involved in this effort, guidelines were prepared to direct the development of these courses.

This process of defining each area and developing courses within it was somewhat untidy and not necessarily sequential. We had determined and announced when students would be required to include these courses in their programs; thereforc, at a specified time, some of these courses had to be offered.

These foci were defined in broad, inclusive ways. Once this was done, we specified the particular topics within these foci that could be offered, because we could not offer everything and did not intend to. These naturally were based on areas of ongoing faculty research; we wanted to exploit our current research strength in recruiting students who were interested in pursuing these areas while showcasing faculty re-

*Ir is important to clarify that although the University of Michigan offers a postbaccalaureate doctoral degree, the nursing specialization described here presumes the completion of a master's-level clinical specialization. search. As these changed over time, so have the courses offered within each focus. Also, as knowledge evolves, so do the courses.

I will now briefly describe how each of the foci is organized and what the current course offerings are.

\section{HEALTH PROMOTION AND RISK REDUCTION}

Scholarship in this focus is concerned with (1) understanding factors that influence at-risk or healthpromoting behaviors throughout the lifespan; (2) identifying interactions between behavioral, biophysical, cultural, and socioeconomic processes that influence at-risk and health-promoting behaviors and related health outcomes; and (3) designing and testing of individual-, group-, and community-level interventions to promote health or reduce risk of individuals and aggregates. This focus also includes knowledge--theory and intervention skills-to promote health of families. Areas of relevant faculty research are shown in Fig 1. Examples of courses within this are Conceptual and Methodological Issues in Health Behavior; Nursing Research Perspectives on the Community: Health, Stress, and Coping; and Family Systems and Health: Theory and Research in Nursing.

\section{ACUTE, CRITICAL, AND LONG-TERM CARE}

This focus was intended to address the spectrum of biobehavioral phenomena that underlie or characterize human responses to illness. As we examined our current faculty strength, it became evident that this was mainly in the neurobehavior domain, which is our focus. Of specific concern were human responses (behaviors) to alterations in neurocognition and/or neu- 
TARGETS FOR INGUIRY

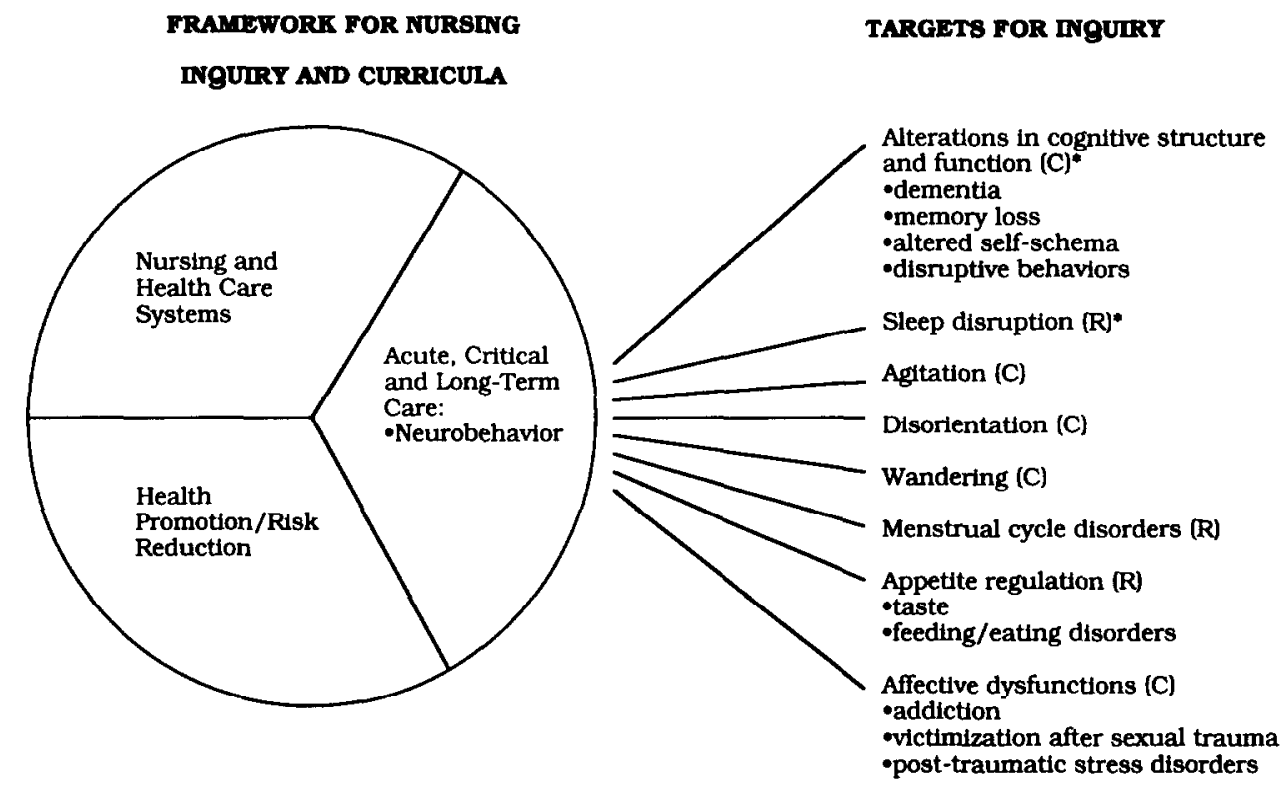

FRAMEWORK FOR NURSING

INGUIRY AND CURRICULA
Figure 2. Conceptual and organization framework for graduate programs at The University of Michigan School of Nursing. (Details provided only for the neurobehavioral focus.) $\mathrm{C}^{*}$, cognition; $R^{*}$, regulation.
SYSTEMS

roregulatory systems as well as alterations at the interface between these two systems and between each system and the environment. Here too, the courses were designed so that we could capitalize on faculty research. Areas of relevant faculty research are shown in Fig 2. Students could not be presumed to have the necessary background; therefore, specific cognates were required. A sequential series of nursing courses were developed so that the first would be an overview of phenomena that can be classified under the neurobehavior rubric; the remaining courses would each focus on specific phenomena currently being investigated by faculty research. All courses focus on theories within specific areas and the methodologies essential to testing, developing, or reformulating theories within the conceptual area of interest. Examples of courses are Human Responses and Altered Biological Function; Human Responses: Altered Memory; Human Responses: Altered Energy Regulation and Cardiovascular Risk; and Cognitive Impairment in the Elderly: Models, Measures, and Methods.
This focus has been somewhat slower to develop than the others; nursing knowledge regarding systems was not well developed; also, we have not had a critical mass of faculty. At present, the faculty is in place, and knowledge accrual in selected areas is such that this focus is now being actively shaped. Several research programs have developed, and a series of doctoral courses recently have been approved by the faculty.

We have conceptualized this focus as representing a number of systems or subsystems, each of which represents an arena or environment in which nursing and health care services are rendered and need to be managed. Examples of these are clinical nursing systems, educational systems, community systems, and occupational systems. This scheme can accommodate other emerging systems as well. Each of these systems has unique knowledge and practice concerns; there are also concerns common to all these systems. This schema is presented in Table 1.

TABLE 1. Schematic Presentation of Nursing and Health Care Systems

\begin{tabular}{|c|c|c|}
\hline $\begin{array}{l}\text { Examples } \\
\text { of Systems }\end{array}$ & $\begin{array}{l}\text { Examples of } \\
\text { System-Specific Concerns }\end{array}$ & $\begin{array}{l}\text { Examples of Concerns } \\
\text { Common Across Systems* }\end{array}$ \\
\hline Clinical nursing systems & Work redesign & $\begin{array}{l}\text { Organizational analysis } \\
\text { Study of leadership } \\
\text { Organizational change }\end{array}$ \\
\hline Educational systems & Facuity productivity & Impact of setting and context on outcomes and performance \\
\hline Community systems & Health policy & Human and material resource management \\
\hline Occupational systems & Health promotion at work & $\begin{array}{l}\text { Information systems/technologies and their uses to accomplish system } \\
\text { goals }\end{array}$ \\
\hline Other systems & & $\begin{array}{l}\text { Analysis of social, political, economic, and other factors that impact } \\
\text { systems } \\
\text { Decision and probability theories }\end{array}$ \\
\hline
\end{tabular}

*Examples apply to all systems. 
Special difficulties presented themselves in formulating our ideas for this focus: (1) the broad scope of the systems represented; (2) varying backgrounds of students (some have clinical backgrounds; others have extensive systems expertise); and (3) the varying career goals of students (some are interested in preparing for executive roles; others wish to administer educational programs on graduation, and the like).

It is our current thinking that in using this schema, knowledge concerns common to all systems might be the basis of course offerings. For students with interests in specific types of systems, subspecializations can be further developed independently, through mechanisms such as individually guided study, selection of appropriate cognate courses, and pursuit of the dissertation with application within the chosen system (Ketefian \& Redman, 1990). Areas of relevant faculty research are shown in Fig 3.

Examples of courses are Nursing Ethics: Theory and Research; Nursing and Health Policy; and Organizational Systems of Nursing Care Delivery.

\section{Interrelations of Curricular Components}

In emphasizing the disciplinary component, it has not been my intent to diminish the importance of other components of the curriculum. None of the pieces can work alone; rather, the elements are interdependent and need to be woven together in such a manner that they make a complete whole and support each other. For example, theory building and philosophy of science enable students to reflect on the nature of our knowledge as it addresses human needs (Fry, 1988). Research methods enable students to evaluate the validity and usefulness/significance of the empirical work they are studying and that are basic to the methodological expertise of scientists. Cognate courses expose students to the broader areas of interdisciplinary knowledge that shed light on the nursing phenomena being studied.

There is another issue of interest here that needs further evaluation. Instead of teaching a series of separate research methods courses, one might integrate this content within the substantive disciplinary courses, enabling students to study those research methods specific to the study of problems under consideration. However, several questions have to be addressed: What are the advantages and disadvantages of these alternate approaches? How might students respond to either approach? Are research concepts acquired within the context of specific subject matter easily transferrable to other contexts? Many disciplines do this, and we may be able to benefit from the experiences of others. In our program we have arrived at a compromise between these two seemingly disparate approaches; we offer some basic research courses and, in addition, each substantive nursing course deals with particular methodological issues specific to that area of inquiry. This combination works well.

\section{Implementation Issues}

Students are required to select three courses from the disciplinary component during their course of study. We have defined these courses as selectives, ie, we offer a range of courses from each focus from which students may select those of interest (as opposed to having only three set courses from each focus that all students must take). Each semester at least one course from each focus is offered so that students pursuing a focus are able to progress.

We have encountered a number of issues during the implementation of this part of the curriculum that I will identify.

Figure 3. Conceptual and organization framework for graduate programs at The University of Michigan School of Nursing. (Details provided only for the systems focus.)

FRAMLWORK FOR NURSING

TARGETS FOR INGUIRY

INGUIRY AND CURRICULA

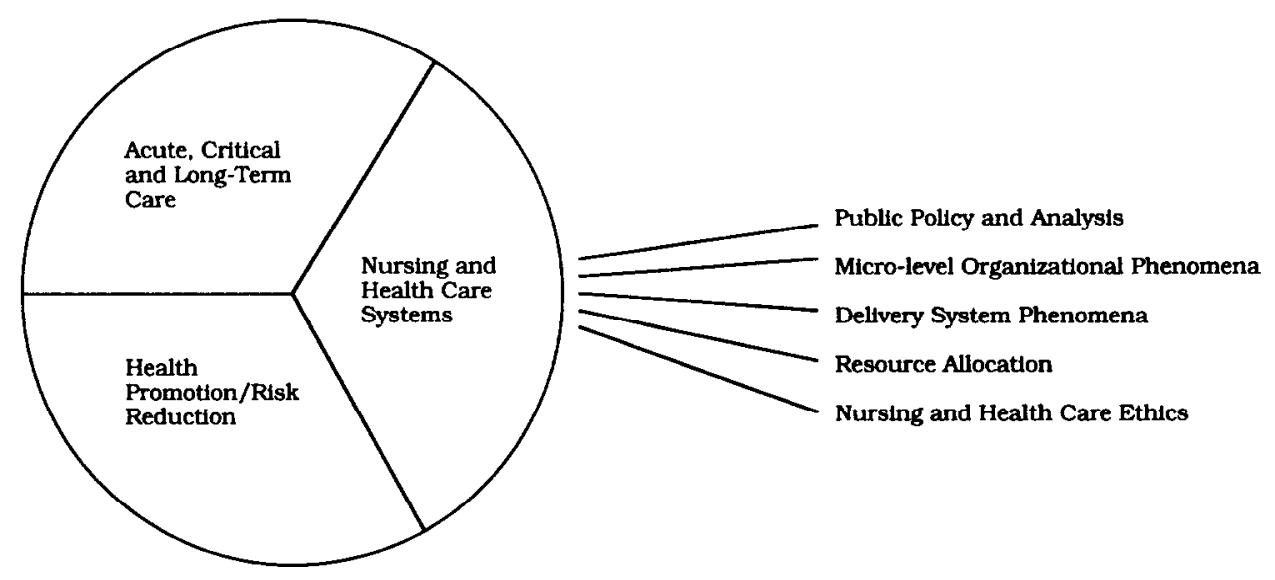


1. We like being able to give choices to students; however, this means that at any given time a course may not be sufficiently filled to make it cost-effective. This also makes planning very difficult, because it is impossible to anticipate accurately the number of students who would enroll in a given course.

2. Another reality that makes planning unreliable is that students do nor move as a cohort through a sequence of courses; some are studying full time and others part time, and they will choose courses both on the basis of curricular requirements as well as their individual scheduling requirements.

3. Perhaps the most complex issues relate to faculty. All courses are designed and taught by faculty members who have an active research program and who are productive scholars in the subject matter. This means that the faculty are not interchangeable. This is a major strength in that students are able to study with those who are producing knowledge and can incorporate their research into their teaching, while helping students identify areas for their own investigation; it also can present some practical hurdles.

In our organizational structure we do not have a scparatc faculty group for the doctoral program, and faculty teach across all levels of study. Therefore, the needs of all programs must be balanced and considered. If a faculty member is unavailable, the course with which she or he is associated cannot be offered and has to be delayed. This means finding a faculty member who is available to teach another course within the given focus, balancing this with student interest at that time.

There are a myriad of such complicating factors that need to be addressed to make implementation a reality while maintaining a rigorous and quality program.

More faculty members are interested in teaching in the doctoral program than are assigned. We have developed clearly understood criteria for faculty participation. There are many points of participation in the doctoral program, and all doctorate-holding faculty have an opportunity to have input into the doctoral program. But only those who are productive scholars and who have a record of teaching excellence are assigned to teach courses and chair dissertation committees. Through an informal system of collegial mentorship, junior faculty are able to serve on student program planning, preliminary examination, and dissertation committees until they successfully develop their programs of research to be in a position of mentoring doctoral students.

4. Another interesting problem is that some fac ulty advisors recommend that their master's students take these courses. Yet, these courses are designed specifically for doctoral students and presuppose completion of all master's level courses; they also presuppose a certain number of doctoral-level core courses as prerequisite or corequisite. The level of discourse in the classroom, the expectations about student participation, and the performance are quite different from those at the master's level. Occasionally, even when a doctoral student is enrolled in these courses before the prerequisites and corequisites, he or she has had some difficulties in maintaining the pace. Therefore, the goals and purposes of these courses need to be continually interpreted to all within the scholarly community so that people do not believe that these decisions are arbitrary.

\section{. we wanted as much peer input as possible during the idea-development phase.}

5. Another issue relates to our course review process. Our school has a highly formalized curriculum and course review procedure that ultimately involve the entire faculty in the process. Also, we wanted as much peer input as possible during the idea-development phase. This entire process could take as long as a year or more for an idea to move into an approved course. Yet, we were under pressure to offer courses so that students could meet program requirements; hence, we could not always wait for formal approval. We solved this problem by using a mechanism available in our institution by offering some of these courses under a "special topics" number. 'This is a one-time course that does not require formal course approval; peer consultation and program director approval are suffi- 
cient. This allowed the faculty a certain degree of flexibility in testing ideas and approaches, obtaining student input, and then submitting the course for formal approval. This has worked very well, and in the long run it resulted in stronger courses while relieving pressure from the faculty.

6. Occasionally, a student wishes to study a subject that is so narrow and so specific that none of the courses would meet his or her need. In these cases we arrange an independent study course. The student enters into a contractual agreement with a particular faculty member and in effect designs a unique course to meet identified needs. Once approved by the program director, such an independently designed course will substitute for one of the nursing courses.

\section{Additional Reflections}

The manner in which we have developed this program area has helped us be very clear to ourselves and our constituencies about what we want to be known for and what we can do best and to become comfortable about the fact that we cannot do everything or meet all possible needs. This has been helpful in student recruitment, and we expect that it will be helpful over time in our faculty recruitment efforts as well.

The essential requirement in implementing this is a critical mass of faculty engaged in scholarship in the chosen area who are simultaneously committed to translating this scholarship into enrichment of academic programs and mentoring of students.
As faculty research interests within the school have crystallized around these three foci, communities of scholars have developed comprised of faculty, postdoctoral fellows, and doctoral students who provide intellectual sustenance and mutual mentorship. As a natural outcome of this, predoctoral and postdoctoral training grants are evolving in these foci. Each of our three groups are at slightly different developmental stages and are learning from each other. This is an evolutionary process that needs to be nurtured and cannot be forced.

There is a downside. There are faculty whose research interests do not readily fit within these three foci. The school is committed to academic freedom in allowing individuals the pursuit of their research interests. This group is not large but does pose a concern in terms of where and how they receive peer support and intellectual sustenance and whether they will be able to get a share of the resources to support their individual efforts. At the same time, it is important to promote the understanding that inclusion within a specific intellectual thrust does not mean that others are being excluded. Thus, in the final analysis, the choice is theirs to make as to whether they want to continue making our institution their intellectual home or to seek an environment more consistent with their pursuits.

\section{Acknowledgment}

The author expresses appreciation to Professors Jean Goeppinger, Carol Loveland-Cherry, Bonnie Metzger, Richard Redman, Lillian Simms, and Ann Whall of the School of Nursing. The University of Michigan, for their thoughtful comments on an earlier draft of this article.

\section{References}

American Nurses' Association. (1985). Directions for nursing research: Toward the twenty-first century. Kansas City, MO: ANA.

Donaldson, S. D., \& Crowley, D. M. (1978). The discipline of nursing. Nursing Outlook, 26, 113-120.

Ellis, R. (1984). Nursing knowledge development. In Proceedings of the National Forum on Doctoral Education in Nursing, (pp. 1-10). Denver, CO: The University of Colorado.

Fitzpatrick, J. J. (1989). Conceptual basis for the organization and advancement of nursing knowledge: Nursing diagnosis/taxonomy. In Proceedings for the 1989 National Forum on Doctoral Education in Nursing. (pp. 33-44). Indianapolis, IN: Indiana University School of Nursing.

Fry, S. T. (1988). The nature of knowledge. In C. Bridges \& N. Wells (Eds.), Fifth nursing science colloquium. strategies for theory development: $V$ (pp. 7-23). Boston: Boston University School of Nursing.

Ketefian, S. , \& Redman, R. (1990). Education for nurs- ing administration: An agenda for the twenty-first century. In Henry B. M. (Ed.), Practice and inquiry for nursing administration (pp. 101-109). Washington, D.C.: American Academy of Nursing.

Kim, H. S. (1989). A conceptual base for the organization and advancement of nursing knowledge: Nursing's metaparadigm domain concepts. In Proceedings for the 1989 National Forum on Doctoral Education in Nursing. (pp. 2132). Indianapolis, IN: Indiana University School of Nursing.

Meleis, A. I. (1988). Doctoral education in nursing: Its present and future. Journal of Professional Nursing, 4(6), 436-446.

Walker, L. (1989). Conceptual bases for the organization and advancement of nursing knowledge: Clinical content. In Proceedings for the 1989 National Forum on Doctoral Education in Nursing. (pp. 6-20). Indianapolis, IN: Indiana University School of Nursing. 